\title{
Persistent Ductus Arteriosus in the Brown-Norway Inbred Rat Strain
}

\author{
REGINA BÖKENKAMP, ADRIANA C. GITTENBERGER-DE GROOT, CONNY J. VAN MUNSTEREN, ROBERT W. GRAUSS, \\ JAAP OTTENKAMP, AND MARCO C. DERUITER
}

\author{
Departments of Pediatric Cardiology [R.B., J.O.], Anatomy and Embryology [A.C.G.-G., C.J.M., M.C.D.], and Cardiology [R.W.G.], \\ Leiden University Medical Center, 2300 RC Leiden, The Netherlands
}

\begin{abstract}
Persistent ductus arteriosus (PDA) is a common cardiovascular anomaly in children caused by the pathologic persistence of the left sixth pharyngeal arch artery. The inbred Brown-Norway (BN) rat presents with increased vascular fragility due to an aortic elastin deficit resulting from decreased elastin synthesis. The strikingly high prevalence of PDA in BN rats in a pilot study led us to investigate this vascular anomaly in 12 adolescent $\mathrm{BN}$ rats. In all $\mathrm{BN}$ rats, a PDA was observed macroscopically, whereas a ligamentum arteriosum was found in adult controls. The macroscopic appearance of the PDA was tubular $(n=2)$, stenotic $(n=8)$, or diverticular $(n$ $=2$ ). The PDA had the structure of a muscular artery with intimal thickening. In the normal closing ductus of the neonatal controls, the media consisted of layers of smooth muscle cells (SMCs) intermingled with layers of elastin. The intima was thin and poor in elastin. By contrast, the media of PDA in $\mathrm{BN}$ rats elastin lamellae were absent and the intima contained many elastic fibers. The abnormal distribution of elastin in the PDA of BN rats suggests that impaired elastin metabolism is related to the persistence of the ductus and implicates a genetically determined factor that may link the PDA with aortic fragility. (Pediatr Res 60: 407-412, 2006)
\end{abstract}

$\mathrm{P}_{\mathrm{R}}$ atent ductus arteriosus is frequently diagnosed in children. Reflecting the increased survival of premature infants the prevalence has risen to $13.5 \%$ of all heart defects at birth (1). Patent ductus arteriosus in premature babies is a functional anomaly, which must be distinguished from the structural anomaly of the PDA in the spectrum of congenital heart disease. To separate those two entities clinically, a PDA is defined as a ductus that has failed to close after 3 months of age (2). In the offspring of patients with PDA, the incidence of this cardiovascular anomaly is increased, suggesting a genetic background (1). Mutations in the transcription factor AP-2 $\beta$ (TFAP2 $\beta$ ) cause familial PDA in Char syndrome (3). Recently, a new aortic aneurysm syndrome has been described due to mutations in the transforming growth factor (TGF) $\beta$ receptors 1 and 2 (TGF $\beta$ R 1 and TGF $\beta$ R2) being associated with PDA and ductal aneurysm in $>50 \%$ of the affected individuals (4). In human PDA, the ultrastructural changes associated with physiologic ductal closure do not occur. Intimal cushion formation is abnormal or absent and the endo-

Received January 11, 2006; accepted May 22, 2006.

Correspondence: Marco C. DeRuiter, Ph.D., Department of Anatomy and Embryology, Leiden University Medical Center, Gebouw 2 S-1-P, PO Box 9600, 2300 RC Leiden, The Netherlands; e-mail:m.c.deruiter@lumc.nl

DOI: 10.1203/01.pdr.0000238243.37116.a6 thelium remains attached to the internal elastic lamina or to an additional subendothelial elastic lamina; invagination of endothelium or migration of SMCs from the media are not observed $(2,5)$.

Until now, the only animal model of inherited PDA has been established in dogs by Patterson and coworkers $(6,7)$. The morphologic changes in canine PDA resemble those in humans. The process of physiologic ductal closure is well studied in various laboratory animals such as rats $(8,9)$, rabbits (9), and lambs (10). The BN rat differs significantly from other strains of rats with respect to thoracic and abdominal aortic elastin content and internal elastic lamina rupture (11). This phenotype has been related to a genetically increased vascular fragility in the BN rat (12). The present study describes the morphologic details of a genetically determined PDA in an inbred strain of BN rats. With our histologic study, a new model of a small laboratory animal with PDA is introduced.

\section{MATERIALS AND METHODS}

Animals. Twelve young adult female $\mathrm{BN}$ (BN/Rij) rats ranging in age between 9 and 11 wk (i.e. about 1-4 wk before fertility), supplied by Harlan Horst (The Netherlands) were studied. In addition to these 12 rats, $18 \mathrm{BN}$ rats from the same age were studied macroscopically in our institution. Fourteen of these rats served as allogenic aortic valve donors in heterotopic aortic valve transplantation experiments published by Grauss et al. (13). Twelve adult Wistar rats and 12 neonatal Wistar rats were used as normal controls. Animal care complied with the Guide for the Care and Use of Laboratory Animals published by the U.S. National Institutes of Health (National Institutes of Health Publication No. 85-23, revised 1996). Animal experiments were approved by the local committee of animal welfare of the Leiden University Medical Center (LUMC).

Experimental protocol. Rats were killed by $\mathrm{CO}_{2}$ inhalation followed by cervical dislocation. Neonatal rats were killed by decapitation. A median sternotomy was performed followed by en bloc removal of the lungs. The ductus arteriosus and the great vessels were inspected and documented photographically. After macroscopic examination, the great vessels and the ductus arteriosus were resected. The specimens were overnight fixed in $4 \%$ paraformaldehyde (PFA) dissolved in phosphate-buffered saline (PBS) or in $2 \%$ acetic acid in $100 \%$ ethanol overnight at $4{ }^{\circ} \mathrm{C}$. Fixed tissues were thoroughly rinsed in PBS and dehydrated in graded ethanol and xylene and embedded in paraffin. Sections of $5 \mu \mathrm{m}$ were cut and mounted onto several series of slides. Standard histologic stainings were performed with hematoxylin and eosin (HE) for a morphologic overview. Resorcin-fuchsin (RF) and sirius red (SR) were used to depict elastin and collagen, respectively. To detect SMCs, the mAb against smooth muscle $\alpha$-actin 1A4 (1:3000; DAKO

Abbreviations: 1A4, monoclonal antibody against smooth-muscle $\alpha$-actin; EC, endothelial cell; HE, hematoxylin-eosin; PDA, persistent ductus arteriosus; RF, resorcin-fuchsin; SMC, smooth muscle cell; SR, sirius red; TFAP2B, transcription factor AP- $2 \beta$ 
A/S Glostrup, Denmark), horseradish peroxidase-conjugated rabbit antimouse antibody (1:250, DAKO) was used as second antibody. The staining procedure was performed as described by Grauss et al. (13). Sections were briefly $(5 \mathrm{~s})$ counterstained with hematoxylin.

\section{RESULTS}

\section{Macroscopy}

Controls (Wistar rats). On analysis within $30 \mathrm{~min}$ after delivery, the ductus appeared as a small blood-filled vessel. Twenty-four hours after delivery, the ductus arteriosus appeared as a whitish strand of vascular tissue. There were no indications of blood inside the ductus. Both the pulmonary and aortic end of the ductus were closed. In the adult Wistar rats, the ductus was a thin ligament hardly discernible from the surrounding tissue.

$B N$ rats. In all adolescent $\mathrm{BN}$ rats, a macroscopically visible ductus arteriosus was found instead of the expected thin ligament. The persistent ductus in the 14 rats that were dissected in the course of heterotopic aortic valve transplantation experiments had to be ligated to avoid hemorrhage after transplantation. There were no signs of hemodynamic consequences of the PDA. In particular, cardiomegaly and pulmonary congestion were not found during dissection of the cardiovascular system. Female rats were able to survive pregnancy and delivery without clinical signs of heart failure. The morphologic characteristics of the ductus in the 12 individual animals of the present study are summarized in Figure 1. The morphologic appearance varied between a longer, more tubular and a short conical structure. The largest ductus measured 25\%-30\% of the diameter of the ascending aorta. (Fig. 2a). The aortic end of the ductus was open in all specimens and filled with blood at dissection. As to the morphology of the pulmonary end of the ductus arteriosus, three different types of ductus could be distinguished: 1) a tubular type with a widely patent pulmonary end in two rats (Fig. 2a), 2) a stenotic type with a stenotic lumen at the pulmonary end filled with a small line of blood in eight rats (Fig. 2b), and 3) a diverticular type with an occluded lumen at the pulmonary end in two rats (Fig. $2 c$ ). Thus, the ductus was completely patent in 10 of 12 rats.

\section{Histology}

Controls (Wistar rats). Functional ductal closure in Wistar rats took place within the first hours after birth. The ductus of neonatal Wistar rats studied within 30 min after birth was still

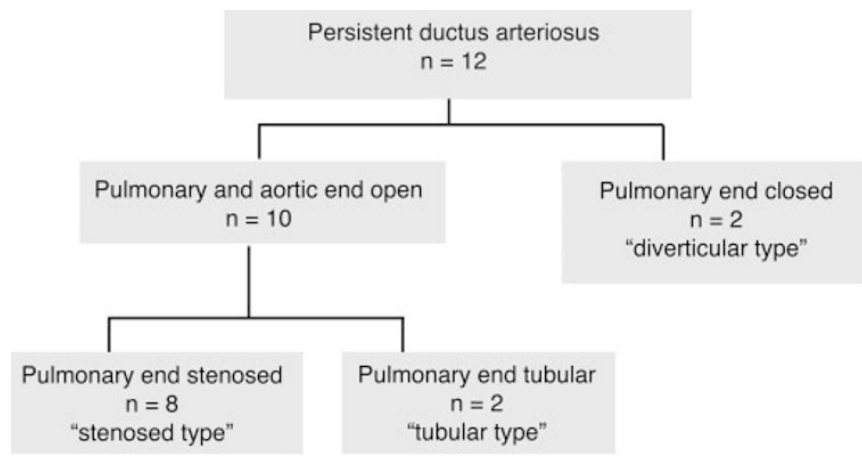

Figure 1. Flowchart illustrating the morphologic findings in BN rats. open. It appeared as an elastic artery with some intimal thickening inside the lumen (Fig. $3 a$ and $b$ ). The media consisted of 10-12 elastin lamellae (Fig. 3b) alternating with layers of SMCs confirmed by 1A4 staining (Fig. 3c) and layers of collagen (Fig. 3d). The inner elastic lamina forming the border between tunica media and intima was thicker than the other lamellae. The intima consisted of three to four layers of vertically oriented cells perpendicular to the circular layers expressing SMC actin. The elastin laminae were irregular and thin. The intima was devoid of collagen layers (Fig. 3d). The outer part of the ductus was formed by four to five layers of loose adventitia tissue containing small amounts of elastin. In all animals studied at the age of $24 \mathrm{~h}$ postpartum, the ductal lumen was closed.

In adult Wistar rats, the ductus arteriosus was degenerated into a ligament. A vascular structure of the ductus arteriosus was not detectable. The Wistar rats showed loosely arranged short elastic fibers accompanied by some SMCs seen at the site where the ductus ligament was connected to the pulmonary artery.

$\boldsymbol{B} \boldsymbol{N}$ rats. The histologic findings confirmed the macroscopic diagnosis of the tubular, stenotic, and diverticular type of the PDA. The pulmonary end of the ductus was histologic patent in 10 of the $12 \mathrm{BN}$ rats. Only in the two animals with the diverticular type PDA was the pulmonary end of the ductus was closed.

All three types of ductus arteriosus had the structure of a muscular artery with intimal thickening (Figs. 4 and 5). Two types of intimal thickening were found. In the two specimens with tubular morphology of the ductus, the intima consisted of six to eight regularly organized elastin lamellae between single layers of SMCs (Fig. $4 a$ and $b$ ). The first intimal elastin lamella was located subendothelially (Fig. $4 a$ and $b$ ). In the remaining 10 ductus, belonging to the stenotic and diverticular groups (Figs. $4 d-f$ and 5), the intimal thickening was less organized than in the tubular type. Areas with elastin lamellae were found neighboring areas of intimal thickening without elastin. In eight of the 10 ductus, small vessels indicating neovascularization of the intima were present (Fig. 5a-d). These vessels consisted of endothelial cells (ECs), elastin lamellae, and SMCs (Fig. 5a-d). Combinations of both types of intimal thickening were also observed. The internal elastic lamina could be identified in all specimens as a boundary between intima and media. In the media, as confirmed by 1A4 staining (Figs. $4 f$ and $5 c$ ), 10 layers of SMCs were found. Elastin lamellae, however, were absent in the media of BN ductus (Figs. $4 a, b, e$ and $5 a$ ) in contrast to the controls (Fig. 3b). The four to five layers of adventitial tissue contained small amounts of elastin (Figs. $4 b$ and $d$ and $5 b$ ). Collagen was predominantly present in the adventitia as in normal controls (Fig. 3d). Related to the internal elastic lamellae and in areas of intimal neovascularization, SR staining was more pronounced in BN rats (Fig. $5 d$ ).

\section{DISCUSSION}

We found a PDA in 9- to 11-wk-old BN rats and failed to do so in control Wistar rats. The PDA in adolescent BN rats 

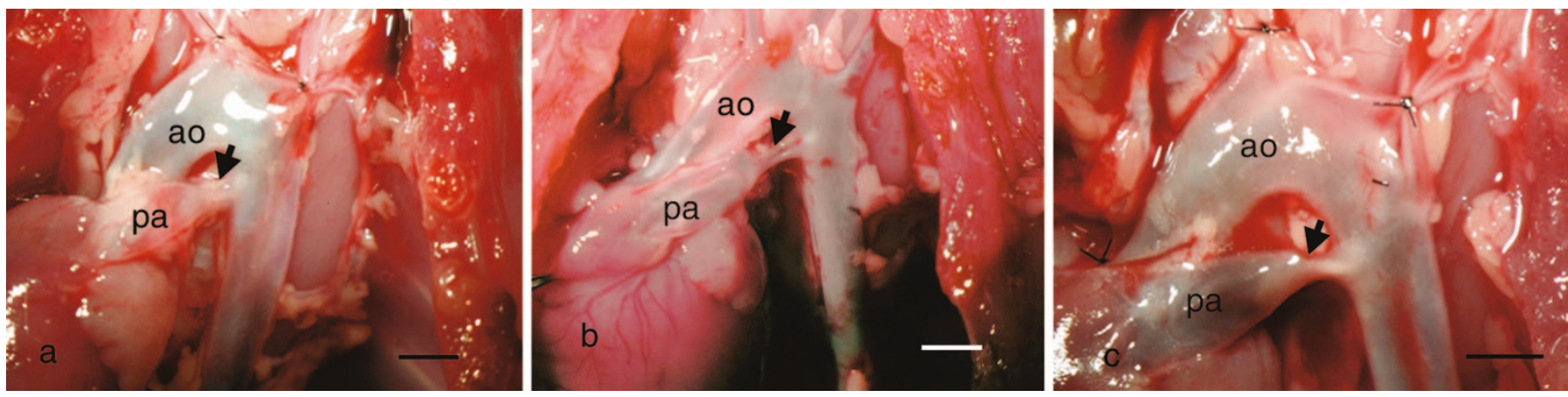

Figure 2. Macroscopic image of the three morphologic types of PDA in adolescent BN-rats: tubular-type PDA (a), stenosed-type PDA (b), diverticular-type PDA $(c)$. ao, aorta ascendens; pa, pulmonary artery; the ductus arteriosus is marked by an arrow. The bar represents $2 \mathrm{~mm}$.
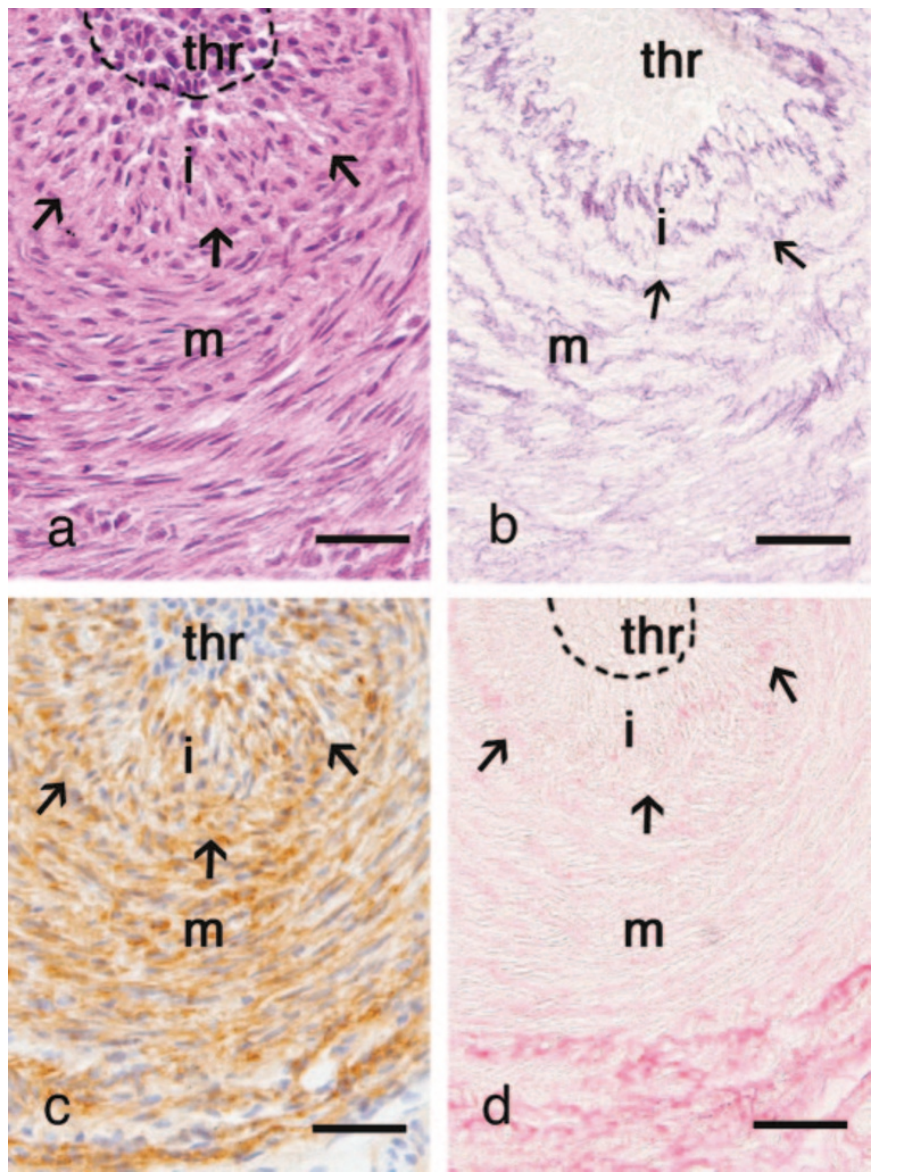

Figure 3. Histology of a physiologically closing ductus arteriosus of a neonatal Wistar rat 30 min post partum. Stained with $\mathrm{HE}(a), \mathrm{RF}(b), 1 \mathrm{~A} 4(c)$, and SR $(d)$. Note three to four layers of intimal thickening and the media consisting of 10-12 elastin lamellae interchanged with collagen layers and layers of SMCs. The internal elastic lamina is indicated by arrows. a, adventitia; m, media; i, intima; thr, thrombus. The bar represents $100 \mu \mathrm{m}$.

was histologically characterized by abundant elastin lamellae in the intima, a subendothelial elastic lamina, and the virtual absence of elastin in the media. By contrast, the normal closing ductus arteriosus in neonatal Wistar rats is an elastic vessel composed of an intima with a thin layer of endothelium and subendothelial connective tissue. The media consists of regularly organized elastin lamellae intermixed with layers of SMCs.
To the best of our knowledge, this is the first report describing hereditary PDA in a specific rat strain. The morphologic characteristics of PDA in BN rats are comparable to the histologic findings both in human and canine PDA $(6,7)$. The functional relevance of PDA in the adolescent BN rats is comparable to a small PDA, which is amenable to catheter interventional treatment in humans. Therefore, this rat strain may serve as a model for human PDA.

$\mathrm{BN}$ rats differ from other rat strains with respect to the elastin content (11) and the rupture of the internal elastic lamina in the thoracic and abdominal aorta (12). This phenotype has been related to increased vascular fragility characteristic of the BN rat (12). Therefore, alterations in elastin regulation may link PDA and the aortic fragility characteristic of BN rats. By analogy, Khau van Kien et al. (14) described the association of PDA and familial thoracic aortic aneurysm and dissection (TAA/AD) in a large French family. Recently, mutations in the MHY11 gene were identified as cause for both TAA/AD and PDA in this family (15).

Elastin in the vascular wall is a polymer of the tropoelastin protein secreted by ECs, SMCs, and fibroblasts (16) Elastin is an autocrine regulator of SMC proliferation (17). In the normal closing ductus, impaired elastogenesis coincides with increased SMC migration and proliferation causing physiologic occlusion (18). By contrast, abundance of elastin lamellae in the intima, a subendothelial elastic lamina, and failure of intimal SMC proliferation are hallmarks of PDA in humans and canine pups (19-21).

PDA in BN rats is also characterized by elastin lamellae in the intima, a subendothelial elastic lamina, and the virtual absence of elastin in the media. The media of the normal closing ductus in rodents is built up by SMCs derived from the neural crest (22) producing elastin lamellae. The absence of elastin in the media of a PDA in BN rats fits into a concept of an overall down-regulation of the aortic elastin production in this particular strain (11). In the normal closing ductus, SMCs from the media migrate through the fragmented internal elastic lamina into the intima and cause intimal proliferation leading to closure of the ductus (7). In PDA, the subendothelial elastic lamina is thought to limit the access of the SMCs from the media to the intima. There is also strong evidence that intima cells arise during development and under pathologic conditions from delamination of ECs (23) and circulating precursors (24). The capability of endothelial-mesenchy- 

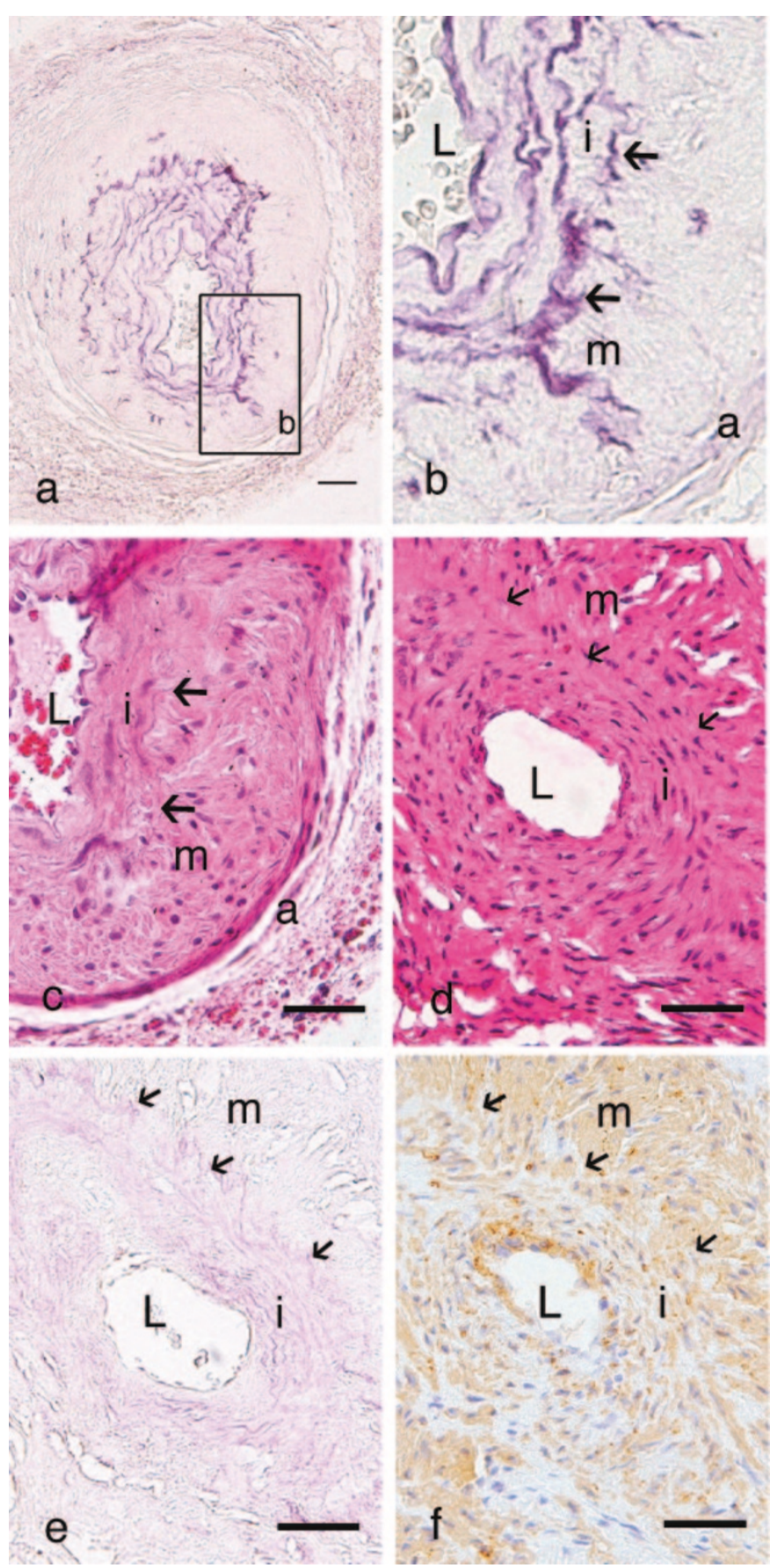

Figure 4. Histology of PDA of adolescent $\mathrm{BN}$ rats stained with $\mathrm{RF}(a, b, e)$, HE $(c, d)$, and anti-smooth muscle actin 1A4 $(f)(a-c)$ The tubular type ductus with subendothelial elastic laminae; $(d-f)$ an example of a stenotic ductus. Here the intimal thickening consists of areas with subendothelial elastic laminae as well as areas with subendothelial accumulations of cells with less elastin. The media is devoid of elastin lamellae in both types of PDA. The internal elastic lamina is indicated by an arrow. a, adventitia; m, media; i, intima. The bar represents $100 \mu \mathrm{m}$.

mal transformation has also been described during arteriogenesis in the embryo (25). As ECs can also produce elastic laminae, the elastic intima in the PDA supports the idea that the mesenchymal cells are derived from the endothelium.

Hence, endothelium-derived SMCs in the intima exhibiting a predominantly secretory phenotype might lead to the excess local elastin production and inhibition of SMC proliferation
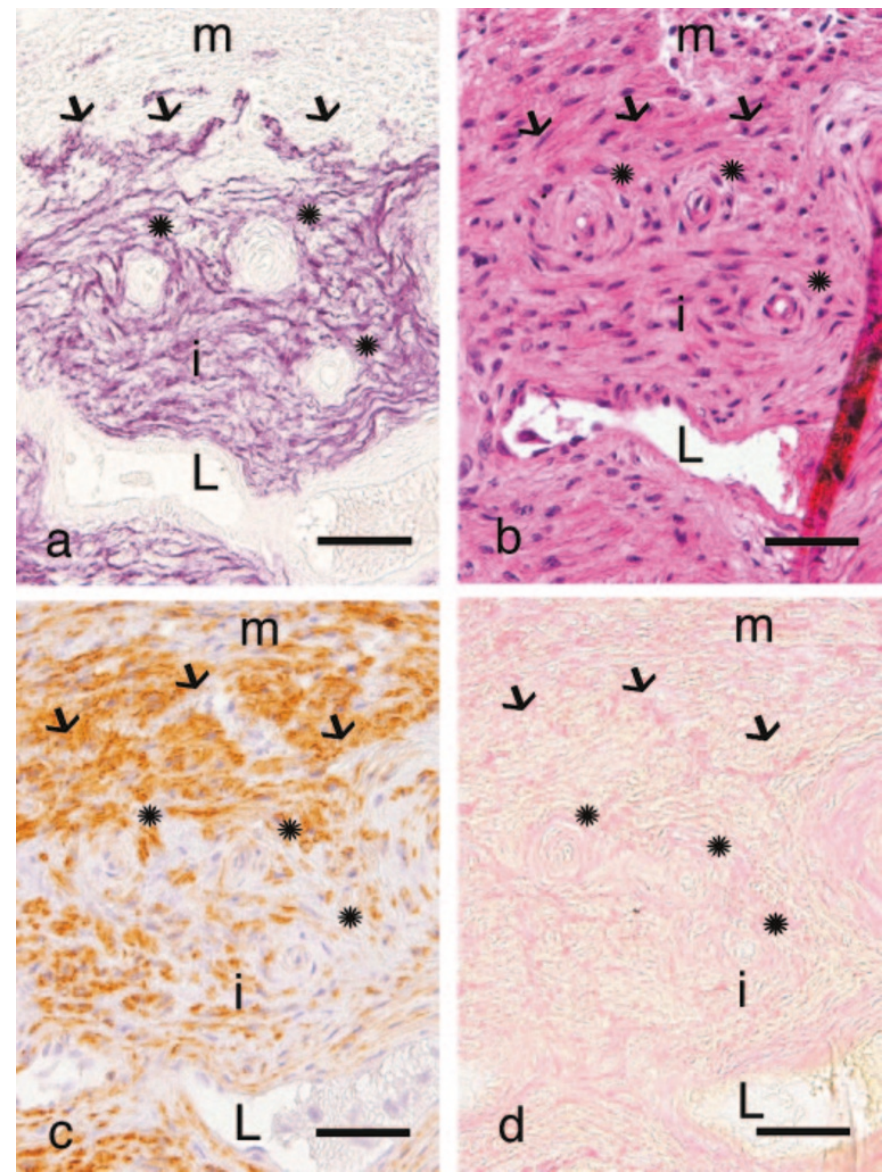

Figure 5. Histology of the intimal neovascularization in PDA of adolescent $\mathrm{BN}$ rats stained with RF $(a), \mathrm{HE}(b)$, anti-smooth muscle actin 1A4 (c), and SR $(d)$. The internal elastic lamina is indicated by an arrow. As in Figure 4, the media is devoid of elastin lamellae. m, media; i, intima; asterisk indicates microvessel. The bar represents $100 \mu \mathrm{m}$.

and closure of the ductus observed in BN rats. The elastinpoor media of PDA may be built up by SMCs of a different origin (probably neural crest cells) lacking secretory properties.

Genetic changes in the physiologic cell differentiation process of the ductus arteriosus might also contribute to the functional heterogeneity of SMCs. During the neonatal period, dedifferentiation of SMCs takes place in the inner intima of the ductus and has been related to intimal thickening and physiologic ductal closure in humans (26). Therefore, a spatiotemporal heterogeneity in differentiation with a lack of neonatal dedifferentiation in the intima of the PDA in BN rats might also be relevant for the development the phenotypic characteristics of PDA.

Elastin synthesis is modulated by various factors. In the rat aorta and in the caudal artery, it has been shown that TGF- $\beta 1$ increases elastin mRNA levels in SMCs and ECs (27). The role of TGF- $\beta$ during ductal closure was established in lambs years ago $(28-30)$. In the present study TGF- $\beta$ signaling was not analyzed because of the fact that the PDA in the adolescent $\mathrm{BN}$ rat represents the endpoint of a defective developmental process.

Several lines of evidence suggest a role of TGF- $\beta$ signaling in congenital cardiovascular anomalies. Recently, a syndrome 
of altered cardiovascular, craniofacial, neurocognitive, and skeletal development caused by mutations in TGF- $\beta$ receptors 1 and 2 has been described (4). The cardiovascular anomalies included aortic root aneurysm and aortic tortuosity in all patients. A PDA or ductal aneurysms were reported in 54\% of the affected individuals. Histologically, the aortic anomaly was characterized by disorganization of the elastin matrix and loss of elastic fiber architecture. Studies on the expression of collagen, connective tissue growth factor, and Smad2 in the aortic media implicated perturbations in TGF- $\beta$ signaling as underlying pathogenetic mechanism. Recent data on Marfan syndrome also focus on mutations of the TGF- $\beta$ receptor. Marfan syndrome, an extracellular matrix disorder with the cardinal cardiovascular manifestations of aortic root dilatation and aneurysm formation, has been associated with defects in the gene encoding for fibrillin at 15q21.1 (31). A second type of Marfan syndrome (MFS II) has been related to locus 3p25-p24.2(32) recently, which has been shown to be caused by heterozygous mutations in the TGFBR2 gene $(32,33)$.

A diverticular phenotype of the ductus was observed in the present study in two of 12 adolescent BN rats. Although strictly speaking, the diverticular ductus is not a patent ductus, it seemed justified to include the diverticular type ductus in study group. The persistence of the aortic end of the ductus as a vascular structure has not been found in rats from other strains i.e. Wistar rats serving as controls. The diverticular type is considered as farthest end of a continuum of PDA. A similar phenotype has been described earlier in dogs with hereditary PDA (7) and is referred to as mixed-type ductus arteriosus. The mixed phenotype consists of stenosis and intimal thickening at the pulmonary end of the ductus and the lack of intimal thickening at the aortic end. In humans, a ductal aneurysm is known as a rare lesion developing in the third trimester of pregnancy (34). This anomaly is observed in connective tissue disorders such as Marfan and Ehlers-Danlos syndromes and other syndromal lesions in about $25 \%$ of the patients (35) and is characterized by deficient or absent intima cushions and/or disorganized elastin lamellae in the ductal media (34). As intima cushion formation (27-30) and elastic fiber organization are both regulated by TGF- $\beta$ signaling, the phenotype of congenital ductal aneurysm might be also the result of localized or generalized perturbations of TGF- $\beta$ signaling.

In eight of $12 \mathrm{BN}$ rats, we observed neovascularization of the intima at the pulmonary end of the ductus. Similar findings have been described in dogs with a hereditary form of PDA. In these genetically defective dogs, the normal process of intimal thickening is impaired. Endothelial strands are observed in the subendothelial region suggestive of capillary formation (7). An important factor leading to abnormal intimal neovascularization is tissue hypoxia. In atherosclerotic systemic arteries, neovascularization develops in response to hypoxia in deep parts of atherosclerotic lesions (35). During physiologic ductal closure, tissue hypoxia appears to be responsible for anatomical closure (36) and has been related to the death of SMCs in the inner media and consecutive vascular remodeling $(26,36)$. The role of tissue hypoxia in ductal closure has extensively been studied in lambs $(37,38)$. In lambs, hypoxic cell death in the media has been attributed primarily to changes in vasa vasorum flow and medial thickness, which can occur before luminal blood flow had ceased (38). In small animals such as rats, mice, and rabbits, intramural vasa vasorum are lacking (39). It has been suggested that, in this situation, the complete obliteration of the ductal lumen is necessary to initiate hypoxia-induced anatomic remodeling of the ductus. The exact mechanisms modulating functional and anatomic closure of the ductus are still not fully elucidated. In vitro data demonstrate a fundamental role for developmentally regulated $\mathrm{O}_{2}$-sensitive $\mathrm{K}^{+}$channels in ductal vascular SMCs during the initial postnatal vasoconstriction of the ductus arteriosus (40). Recent evidence suggests a role for endothelin as oxygen messenger in the ductus during the acute postnatal increase in oxygen tension (41).

\section{CONCLUSION}

The BN inbred rat strain has been characterized as a novel animal model of PDA. PDA in the BN rat may reflect the well-known elastin defect in this particular strain. The BN rat may serve as a model for defective vascular remodeling found in human PDA as well as in human thoracic aortic aneurysm and dissection.

\section{REFERENCES}

1. Morris CD 2001 Epidemiology of congenital heart disease In: Crawford MH, Di Marco JP (eds) Cardiology. Mosby International limited, London, p 1.3.

2. Gittenberger-de Groot AC 1977 Persistent ductus arteriosus: most probably a primary congenital malformation. Br Heart J 39:610-618

3. Satoda M, Zhao F, Diaz GA, Burn J, Goodship J, Pierpont ME, Sweeney E, Thomson EM, Gelb BD 2000 Mutations in TFAP2B cause Char syndrome a familial form of patent ductus arteriosus. Nat Genet 25:42-46

4. Loeys BL, Chen J, Neptune ER, Judge DP, Podowski M, Holm T, Meyers J, Leitch CC, Katsanis N, Sharifi N, Xu FL, Myers LA, Spevak PJ, Cameron DE, De Backer J, Hellemans J, Chen Y, Davis EC, Webb CL, Kress W, Coucke P, Rifkin DB, De Paepe AM, Dietz HC 2005 A syndrome of altered cardiovascular, craniofacial, neurocognitive and skeletal development caused by mutations in TGFBR1 or TGFBR2. Nat Genet 37:275-281

5. Gittenberger-de Groot AC, van Ertbruggen I, Moulaert AJ, Harinck E 1980 The ductus arteriosus in the preterm infant: histological and clinical observations. J Pediatr 96:88-93

6. Patterson DF, Pyle RL, Buchanan JW, Trautvetter E, Abt DA 1971 Hereditary PDA and its sequelae in dog. Circ Res 29:1-13

7. Gittenberger-de Groot AC, Strengers JL, Mentink M, Poelmann RE, Patterson DF 1985 Histologic studies on normal and persistent ductus arteriosus in the dog. J Am Coll Cardiol 6:394-404

8. Hornblad PY 1969 Embryological observations of the ductus arteriosus in the guinea pig, rabbit, rat and mouse. Studies on closure of the ductus arteriosus. IV. Acta Physiol Scand 76:49-57

9. Momma K, Ito T, Mori Y, Yamamura Y 1992 Perinatal adaptation of the cardiovascular system. Early Hum Dev 29:167-170

10. Hornblad PY, Larsson KS, Marsk L 1969 Studies on closure of the ductus arteriosus. VII. Closure rate and morphology of the ductus arteriosus in the lamb. Cardiologia 54:336-342

11. Behmoaras J, Osborne-Pellegrin M, Gauguier D, Jacob MP 2004 Characteristics of the aortic elastic network and related phenotypes in seven inbred rat strains. Am J Physiol Heart Circ Physiol 288:H769-H777

12. Capdeville M, Coutard M, Osborne-Pellegrin MJ 1989 Spontaneous rupture of the internal elastic lamina of the rat: the manifestation of a genetically determined factor, which may be linked to vascular fragility. Blood Vessels 26:197-212

13. Grauss RW, Hazekamp MG, van Vliet S, Gittenberger-de Groot AC, DeRuiter MC 2003 Decellularization of rat aortic valve allografts reduces leaflet destruction and extracellular matrix remodeling. J Thorac Cardiovasc Surg 126:2003-2010

14. Khau Van Kien P, Wolf JE, Mathieu F, Zhu L, Salve N, Lalande A, Bonnet C, Lesca G, Plauchu H, Dellinger A, Nivelon-Chevallier A, Brunotte F, Jeunemaitre X 2004 Familial thoracic aortic aneurysm/dissection with patent ductus arteriosus: genetic arguments for a particular pathophysiological entity. Eur J Hum Genet 12:173-180

15. Zhu L, Vranckx R, Van Kien PK, Lalande A, Boisset N, Mathieu F, Wegman M, Glancy L, Gasc JM, Brunotte F, Bruneval P, Wolf JE, Michel JB, Jeunemaitre X 2006 Mutations in myosin heavy chain 11 cause a syndrome associating thoracic aortic aneurysm/aortic dissection and patent ductus arteriosus. Nat Genet 38:343349 
16. Kagan HM, Trackman PC 1991 Properties and function of lysyl oxidase. Am J Respir Cell Mol Biol 5:206-210

17. Karnik SK, Brooke BS, Bayes-Genis A, Sorensen L, Wythe JD, Schwartz RS, Keating MT, Li DY 2003 A critical role for elastin signaling in vascular morphogenesis and disease. Development 130:411-423

18. Hinek A, Rabinovitch M 1993 The ductus arteriosus migratory smooth muscle cell phenotype processes tropoelastin to a $52-\mathrm{kDa}$ product associated with impaired assembly of elastic laminae. J Biol Chem 268:1405-1413

19. de Reeder EG, Girad N, Poelman RE, van Munsteren JC, Patterson DF, Gittenberger-de Groot AC 1988 Hyaluronic acid accumulation and endothelial detachment in intimal thickening of the vessel wall: the normal and genetically defective ductus arteriosus. Am J Pathol 132:574-585

20. de Reeder EG, van Munsteren CJ, Poelmann RE, Patterson DF, Gittenberger-de Groot AC 1990 Changes in distribution of elastin and elastin receptor during intimal cushion formation in the ductus arteriosus. Anat Embryol (Berl) 182:473-480

21. Slomp J, van Munsteren JC, Poelmann RE, de Reeder EG, Bogers AJ, Gittenberger-de Groot AC 1992 Formation of intimal cushions in the ductus arteriosus as a model for vascular intimal thickening. An immunohistochemical study of changes in extracellular matrix components. Atherosclerosis 93:25-39

22. Molin DG, Poelmann RE, DeRuiter MC, Azhar M, Doetschman T, Gittenberger-de Groot AC 2004 Transforming growth factor beta-SMAD2 signaling regulates aortic arch innervation and development. Circ Res 95:1109-1117

23. Gittenberger-de Groot AC, DeRuiter MC, Bergwerff M, Poelmann RE 1999 Smooth muscle cell origin and its relation to heterogeneity in development and disease. Arterioscler Thromb Vasc Biol 19:1589-1594

24. Hirschi KK, Majesky MW 2004 Smooth muscle stem cells. Anat Rec A Discov Mol Cell Evol Biol 276:22-33

25. DeRuiter MC, Poelmann RE, VanMunsteren JC, Mironov V, Markwald RR, Gittenberger-de Groot AC 1997 Embryonic endothelial cells transdifferentiate into mesenchymal cells, expressing smooth muscle actins in vivo and in vitro. Circ Res $80: 444-451$

26. Slomp J, Gittenberger-de Groot AC, Glukhova MA, van Munsteren JC, Kockx MM, Schwartz SM, Kotelansky V 1997 Differentiation, dedifferentiation, and apoptosis of smooth muscle cells during the development of the human ductus arteriosus. Arterioscler Thromb Vasc Biol 17:1003-1009

27. Sauvage M, Hinglais N, Mandet C, Badier C, Deslandes F, Michel JB, Jacob MP 1998 Localization of elastin mRNA and TGF-betal in rat aorta and caudal artery as a function of age. Cell Tissue Res 291:305-314

28. Boudreau N, Clausell N, Boyle J, Rabinovitch M 1992 Transforming growth factor-beta regulates increased ductus arteriosus endothelial glycosaminoglycan synthesis and a post-transcriptional mechanism controls increased smooth muscle fibronectin, features associated with intimal proliferation. Lab Invest 67:350-359

29. Tannenbaum JE, Waleh NS, Mauray F, Breuss J, Pytela R, Kramer RH, Clyman RI 1995 Transforming growth factor beta 1 inhibits fetal lamb ductus arteriosus smooth muscle cell migration. Pediatr Res 37:561-570
30. Zhou B, Coulber C, Rabinovitch M 1998 Tissue-specific and developmental regulation of transforming growthfactor-beta 1 expression in fetal lamb ductus arteriosus endothelial cells. Pediatr Res 44:865-872

31. Dietz HC, Cutting GR, Pyeritz RE, Maslen CL, Sakai LY, Corson GM, Puffenberge EG, Hamosh A, Nanthakumar EJ, Curristin SM, Stetten G, Meyers DA, Francomano CA 1991 Marfan syndrome caused by a recurrent de novo missense mutation in the fibrillin gene. Nature 352:337-339

32. Collod G, Babron MC, Jondeau G, Coulon M, Weissenbach J, Dubourg O, Bourdarias JP, Bonaiti-Pellie C, Junien C, Boileau C 1994 A second locus for Marfan syndrome maps to chromosome 3p24.2-p25. Nat Genet 8:264-268

33. Mizuguchi T, Collod-Beroud G, Akiyama T, Abifadel M, Harada N, Morisaki T, Allard D, Varret M, Claustres M, Morisaki H, Ihara M, Kinoshita A, Yoshiura K, Junien C, Kajii T, Jondeau G, Ohta T, Kishino T, Furukawa Y, Nakamura Y, Niikawa N, Boileau C, Matsumoto N 2004 Heterozygous TGFBR2 mutations in Marfan syndrome. Nat Genet 36:855-860

34. Dyamenahalli U, Smallhorn JF, Geva T, Fouron JC, Cairns P, Jutras L, Hughes V, Rabinovitch M, Mason CA, Hornberger LK 2000 Isolated ductus arteriosus aneurysm in the fetus and infant: a multi-institutional experience. J Am Coll Cardiol 36:262-269

35. Celletti FL, Waugh JM, Amabile PG, Brendolan A, Hilfiker PR, Dake MD 2001 Vascular endothelial growth factor enhances atherosclerotic plaque progression. Nat Med 7:425-429

36. Clyman RI, Chan CY, Mauray F, Chen YQ, Cox W, Seidner SR, Lord EM, Wiess H, Wale N, Evan SM, Koch CJ 1999 Permanent anatomic closure of the ductus arteriosus in newborn baboons: the role of postnatal constriction, hypoxia, and gestation. Pediatr Res 45:19-29

37. Kajino H, Goldbarg S, Roman C, Liu BM, Mauray F, Chen YQ, Takahashi Y, Koch CJ, Clyman RI 2002 Vasa vasorum hypoperfusion is responsible for medial hypoxia and anatomic remodelling in the newborn lamb ductus arteriosus. Pediatr Res 51:228-235

38. Goldbarg S, Quinn T, Waleh N, Roman C, Liu BM, Mauray F, Clyman RI 2003 Effects of hypoxia and hypoglycemia, and muscle shortening on cell death in the sheep ductus arteriosus. Pediatr Res 54:204-211

39. Wolinsky H, Glasgov S 1967 Nature of species differences in medial distribution of aortic vasa vasorum in mammals. Circ Res 20:409-421

40. Thebaud B, Michelakis ED, Wu XC, Moudgil R, Kuzyk M, Dyck JR, Harry G, Hashimoto K, Haromy A, Rebeyka I, Archer SL 2004 Oxygen-sensitive Kv channel gene transfer confers oxygen responsiveness to preterm rabbit and remodeled human ductus arteriosus: implications for infants with patent ductus arteriosus. Circulation 110:1372-1379

41. Keck M, Resnik E, Linden B, Anderson F, Sukovich DJ, Herron J, Cornfield DN 2005 Oxygen increases ductus arteriosus smooth muscle cytosolic calcium via release of calcium from inositol triphosphate-sensitive stores. Am J Physiol Lung Cell Mol Physiol 288:L917-L923 